\title{
Respiratory sleep disorders in Jeune syndrome: a case description
}

\author{
P. CONGIU', M. PULIGHEDDU', G. GIOI', M. MARICA², C. PANI², S. PIGA², \\ F. MARROSU', L. BOCCONE
}

' Sleep Disorders Center, Departement of Public Health and Clinical and Molecular Medicine, University of Cagliari; ${ }^{2}$ U.O. clinic genetics and rare disease, pediatric division II, Microcitemic Hospital, Cagliari

A B S T R A C T

Purpose: Jeune syndrome (JS, also described as asphyxiating thoracic dystrophy, ATD) is a rare autosomal recessive skeletal dysplasia characterized by a small, narrow chest and variable limb shortness with a considerable neonatal mortality as a result of respiratory distress. Significant life-threatening cervical spine abnormalities can be typical.

Method: Here we describe the case of a male infant of Sardinian origin, who developed respiratory distress and feeding difficulties from the first months, correlated with muscle $\backslash$ skeletal dysmorphism prevalent on chest. Nocturnal respiratory sleep alterations were reported from parents.

Results: After clinical, genetics, radiographic and cervical MRI investigations, ATD diagnosis with C1 stenosis. A full-night video-polysomnographic study was performed in order to evaluate the sleep apnea condition. The study showed a condition of tachipnea \tachicardia, with several short respiratory events during sleep, both obstructive and central type with apneahypopnea index (AHI) 17/ h, mean duration $3.7 \mathrm{sec}$ with longest $20 \mathrm{sec}$.

Conclusion: It can be hypothesized that the combination of altered respiratory and cardiac frequency is related to central type of sleep respiratory disorders consequent to $\mathrm{Cl}$ compression, while the obstructive minor component is related to thoracic restrictive disorders. Full night lab-polygraphy is recommended in dysmorphic skeletal disorders like JS.

Key words

Asphyxiating thoracic dystrophy $\bullet$ Jeune syndrome $\bullet$ Sleep apnea $\bullet$ Cardio-respiratory monitoring $\bullet$ Cervical stenosis

\section{Introduction}

Jeune syndrome (JS), described as asphyxiating thoracic dystrophy (ATD), is a rare autosomal recessive skeletal dysplasia characterized by a small, narrow chest and variable limb shortness with a considerable neonatal mortality as a result of respiratory distress. Renal, hepatic, pancreatic and ocular complications may occur later in life. First described in 1955 by Jeune et al. with the incidence ranges from $1 / 100,000$ to 300,000 live births, the inheritance of ATD is autosomal recessive and a locus has been identified on chromosome $15 \mathrm{q} 13(1)(2)$. There is commonly a high mortality rate due to severe respiratory insufficiency secondary to chest hypoplasia
(3). The differential diagnosis includes spondyloepiphyseal dysplasia, achondroplasia, and Ellis-van Creveld syndrome. Antenatal examination is possible by ultrasound, but the precise diagnosis is very difficult or impossible. Key factors in the prenatal diagnosis are an abnormal small thorax, short limbs, polyhydramnios, and unidentifiable foetal respiratory movements (4)(5).

Most patients experienced respiratory problems in the first years of their life (6). On radiograph, the thoracic and lumbar spine appears relatively normal in height and width. The ribs are thickened, uniformly transverse in orientation, and the chest appears narrowed from both primary shortening of the ribs and additional volume depletion deformity; lungs 
often have chronic atelectasis because of the compression of the surrounding chest (7). Spine problems in JS can be serious with significant and typical life-threatening cervical spine abnormalities. First noted in an autopsy specimen, the posterior arch of $\mathrm{C} 1$ in this syndrome can assume the same dysmorphic shape as the costal-chondral junctions of the chest, curving anteriorly to compress the spinal cord. On lateral C spine films and CT scan reconstruction the posterior arch of $\mathrm{C} 1$ appears hypoplastic, with narrowing of the canal from anterior excursion of the posterior arch into the canal with MRI demonstrating compression of the cord (8).

There is severe thoracic insufficiency syndrome from the Type IIIb with volume depletion deformity in JS. Approximately $60 \%$ to $70 \%$ of patients die from respiratory insufficiency in early infancy and severe restrictive lung disease is common in older survivors.

To our knowledge, no respiratory sleep alteration with nocturnal polygraphic description has been reported in literature in early infancy in this syndrome. Furthermore, none of the case description reported in literature did mention about sleep respiratory monitoring although severe respiratory distress has been described and medical treatment such as night-time CPAP or BiPAP is suggested (9). Only recently, Leroy et al. mentioned about a possible role of respiratory sleep disorders and sleep fragmentation and recommended polysomnography in JS (10). Furthermore, sleep apnea (both central and obstructive types) can be evaluated. Central apnea, in fact, can be idiopathic, but it can also manifests secondary to another medical condition (central sleep apnea syndrome -CAS), which may be caused among others: heart failure (11) high altitude-breathing or use of opioid-based medication (12), by brainstem abnormalities. It is already assumed that central apneas are common during the neonatal period, especially in premature newborns. They may manifest as isolated apneas or as an unstable breathing pattern also known as periodic breathing (13) (14) (15). It can be explained by an immature chemo-responsiveness to $\mathrm{CO} 2$ and $\mathrm{O} 2$, which takes up to 44 weeks and one year respectively to fully develop (16) (15). Consequently, the number of central apneas diminishes with increasing age, but may persist however in an immature central nervous system, which may be present in brain-impaired children (13). Gozal also proposed a theory that primary central neural dysfunction contributes to the genesis and maintenance of sleep disordered breathing. OSAS may also be related to $\mathrm{CJ}$ and a considerable overlap is present due to thorax deformity (17). Since to our knowledge data on respiratory sleep disorders in JS patients are absent, here we describe a clinical and polygrafic study of a Jeune syndrome aimed at evaluate sleep breathing disorders by time and strongly suggest a polygraphic sleep monitoring in this type of patients in order to support a therapeutic ventilator approach.

\section{Case description}

Here we describe the case of a male infant (F.A.), actually 24 months old, only child born to nonconsanguineous, apparently healthy parents of Sardinian origin. The pregnancy was uneventful but prenatal routine ultrasound had shown short femora. The delivery occurred at gestational age 37 weeks with a birth length of $47 \mathrm{~cm}$ (25\% ile) and weight of 2580 gr (10\%ile).

Physical examination at the age of 3 months showed a disproportionate short stature with height below the third centile, rhizomelic shortening with brachydactyly of all digits and relative macro-cephaly and there was no polydactyly. From the first months he developed respiratory distress and feeding difficulties. Chest was extremely small; the respiratory rate was 50/minute with an increased work of breathing and sub-costal recession. Skeletal radiographs showed a cervical spinal stenosis, narrow thorax, short ribs, long clavicles, and a small pelvis, with short iliac bones and a trident appearance of the acetabular margins. Renal ultrasound revealed no abnormalities.

Genetic investigations for mostly common mutations IFT80, DYNC2H1 and TTC221B were negative.

In the first months, he suffered from increasing respiratory distress and he was admitted several times with cyanosis, hypotonia and lost of consciousness in two episodes. During this two episodes, hemogasanalysis revealed severe respiratory distress and alkalosis, the chest radiograph showed a narrow thorax with short ribs (Fig.), without infection. Treatment with oxygen therapy high flow and upper 


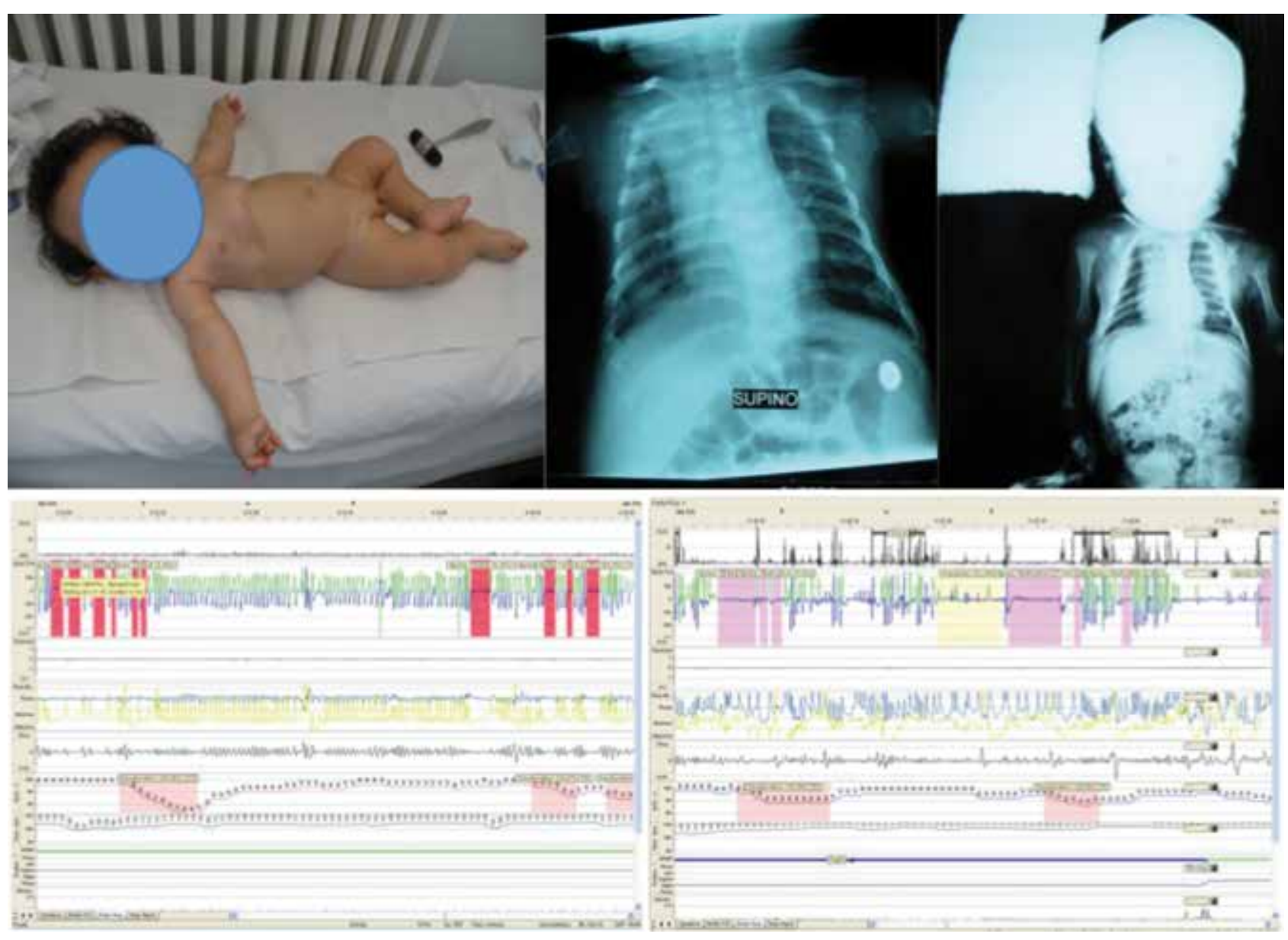

Fig. 1. - Image and radiographs of F.A. at the age of 12 months, showing the typical skeletal abnormalities of ATD. Bottom: A full-night, laboratory-based, polygraphic cardiorespiratory study (PCRS) was performed by means of - Embletta®, manually analysed with software Somnologica_Studio ${ }^{\circledR}$ which evidence of both central (left) and obstructive (right) respiratory events associated with oxygen desaturation (see text for details).

Instrumental data (image, radiographs and PCRS) were acquired during the same recovery.

respiratory aspiration system induced temporary complete recover. After that, a Magnetic Resonance Imaging of cervical spine was performed at the age of 4 months, which revealed cervical canal stenosis, specifically at the occipito-cervical junction with antero-posterior maximum canal diameter of $2 \mathrm{~mm}$ without visible lesions of medulla.

Since spinal cord compression at $\mathrm{C} 1$ with no signal of cerebrospinal fluid at that level was determined and especially because patient was symptomatic, then posterior $\mathrm{C} 1$ decompression and occipito-cervical spine fusion surgical intervention was performed. After that, major respiratory distress events disappeared; stable high frequency respiratory was observed during clinical ambulatory evaluation as follow-up.

At the age of twelve months the parents observed respiratory alterations during sleep and for that rea- son, the baby was admitted to our sleep laboratory centre in order to evaluate possible sleep apnea condition. An ENT (ear, nose and throat) examination excluded adeno-tonsillar hypertrophy.

A full-night, laboratory-based, video-polysomnographic study was performed by means of cardiorespiratory - Embletta ${ }^{\circledR}$, manually analysed with software Somnologica_Studio ${ }^{\circledR}$ (analysed time 552 $\mathrm{min})$. First, we quantified the duration of total sleep time based on the period during which breathing was regular. Then we determined the baseline-breathing rate by calculating the average of the breathing rate at the beginning of sleep, just before wake-up and once in between. Third, the nasal, abdominal, thoracic and $\mathrm{SpO} 2$ signals for patterns indicative of various forms of abnormal breathing were assessed (18)(19)(20). Apneas were scored if $\geq 80 \%$ of flow 
was reduced. To account for age-related variability in respiratory rate, the minimum length of an event in seconds was equivalent to two breaths (13)(19) (21). Apneas associated with $\geq 4 \%$ reduction in $\mathrm{SpO} 2$ from baseline were all included regardless of length. Due to a lack of electroencephalography, arousals could not be scored reliably and were therefore not used as a criterion. Sigh apneas were excluded from analyses.

The study showed a condition of tachypnea with 60 acts $\backslash$ min and rapid cardiac frequency (120 bpm mean, range 93-164). Several short respiratory events during sleep were noted: the apnea-hypopnea index (AHI) was 17/ h (mean duration $3.7 \mathrm{sec}$ with longest $20 \mathrm{sec}$ ). Among the events, majority of them (42\%) were central type (mean duration $3.1 \mathrm{~s}$ ), $16 \%$ obstructive, 3\% mixed and 40\% hypopnea. The respiratory phenomena, present in all nocturnal sleep time were associated with oxygen desaturation (oxygen saturation nadir was 86\%) (Fig.1).

This respiratory disorders initially induced clinicians to start a pressurometriclpressovolumetric ventilatory treatment during sleep, but the severe cervical hypotonia associated with the cervical stenosis condition, which contraindicate manipulation or particular neck movements, suggested to postpone a ventilatory nocturnal treatment to a severe desaturation condition. For that, child is daily monitored with average saturation of $98 \%$ during wake and $94 \%$ during sleep.

It can be hypothesized that the combination of altered respiratory and cardiac frequency is related to central type of sleep respiratory disorders consequent to $\mathrm{C} 1$ compression, while the obstructive minor component is related to thoracic restrictive disorders similar to other dysmorphic skeletal and neuromuscular genetic disorders.

\section{Acknowledgments}

We thank Mrs Josè Garau TNFP, for her expert technical assistance.

The authors declare that they have no conflict of interest.

Manuscript was realised without financial support and performed at the ${ }^{\circ}$ Sleep Centre, Department of Neurological and Cardiovascular Sciences, University of Cagliari
Written informed consent to use anagraphic, clinical and information and images of the baby was obtained from the mother.

\section{References}

Abu-Shaweesh J.M. and Martin R.J. Neonatal apnea: what's new? Pediatr. Pulmonol., 43: 937-944, 2008 .

Berry R.B., Budhiraja R., Gottlieb D.J., Gozal D., Iber C., Kapur V.K., Marcus C.L., Mehra R., Parthasarathy S., Quan S.F., Redline S., Strohl K.P., Davidson Ward S.L., Tangredi M.M. Rules for Scoring Respiratory Events in Sleep: Update of the 2007 AASM Manual for the Scoring of Sleep and Associated Events. $J$. Clin. Sleep Med., 8: 597-619, 2012.

Brouilette R., Hanson D., David R., Klemka L., Szatkowski A., Fernbach S., Hunt C. A diagnostic approach to suspected obstructive sleep apnea in children. J. Pediatr., 105: 10-14, 1984.

Campbell R.M. Spine deformities in rare congenital syndromes: clinical issues. Spine, 34: 1815-1827, 2009.

Chen C.P., Lin S.P., Liu F.F., Jan S.W., Lin S.Y., Lan C.C. Prenatal diagnosis of asphyxiating thoracic dysplasia (Jeune syndrome). Am. J. Perinatol., 13: 495-498, 1996.

Cortina H., Beltran J., Olague R., Ceres L., Alonso A., Lanuza A. The wide spectrum of the asphyxiating thoracic dysplasia. Pediatr. Radiol., 8: 93-99, 1979.

den Hollander N.S., Robben S.G., Hoogeboom A.J., Niermeijer M.F., Wladimiroff J.W. Early prenatal sonographic diagnosis and follow-up of Jeune syndrome. Ultrasound Obstet. Gynecol., 18: 378383, 2001.

de Vries J., Yntema J.L., van Die C.E., Crama N., Cornelissen E.A.M., Hamel B.C.J. Jeune syndrome: description of 13 cases and a proposal for follow-up protocol. Eur. J. Pediatr., 169: 77-88, 2010.

Eckert D.J., Jordan A.S., Merchia P., Malhotra A. Central sleep apnea: Pathophysiology and treatment. Chest, 131: 595-607, 2007.

Gozal D. The brain in sleep-disordered breathing: is it the chicken or is it the egg? Am. J. Respir. Crit. Care Med., 166: 1305-1306, 2002.

Guilleminault C. Obstructive sleep apnea syndrome and its treatment in children: areas of agreement and controversy. Pediatr. Pulmonol., 3: 429-436, 1987. 
Iber C., Ancoli-Israel S., Chesson A.L., Quan S.F. The AASM Manual for the Scoring of Sleep and Associated Events: Rules, Terminology and Technical Specifications. 2007, Westchester IL: AASM

Jeune M., Beraud C., Carron R. Asphyxiating thoracic dystrophy with familial characteristics. Arch. françaises pédiatrie, 12: 886-891, 1955.

Kajantie E., Andersson S., Kaitila I. Familial asphyxiating thoracic dysplasia: clinical variability and impact of improved neonatal intensive care. $J$. Pediatr., 139: 130-133, 2001.

Leroy P., Martens M., Schott N., Cobben N.. Late respiratory failure in Jeune syndrome. Eur. $J$. Pediatr., 169: 375-376, 2010.

Morgan N.V., Bacchelli C., Gissen P., Morton J., Ferrero G.B., Silengo M., Labrune P., Casteels I., Hall C., Cox P., Kelly D.A., Trembath R.C., Scambler P.J., Maher E.R., Goodman F.R., Johnson C.A. A locus for asphyxiating thoracic dystrophy, ATD, maps to chromosome 15q13. J. Med. Genet., 40: 431-435, 2003.

Poets C.F. Apnea of prematurity: What can observational studies tell us about pathophysiology? Sleep Med., 11: 701-707, 2010.

Schäfer T. and Schläfke M.E. Postnatal development of breathing control. Pneumologie, 51: 411-414, 1997.

Schulz R., Blau A., Börgel J., Duchna H.W., Fietze I., Koper I., Prenzel R., Schädlich S., Schmitt J., Tasci S., Andreas S. Sleep apnea in heart failure. Eur. Respir. J., 29: 1201-1205, 2007.

Tüysüz B., Bariş S., Aksoy F., Madazli R., Ungür S., Sever L. Clinical variability of asphyxiating thoracic dystrophy (Jeune) syndrome: Evaluation and classification of 13 patients. Am. J. Med. Genet. A., 149: 1727-1733, 2009.

Ward S.L. and Marcus C.L. Obstructive sleep apnea in infants and young children. J. Clin. Neurophysiol., 13: 198-207, 1996. 